\title{
(t)
}

\section{EMENTA DO GTP QUESTÃO AGRÁRIA, URBANA, AMBIENTAL E SERVIÇO SOCIAL}

\section{Proposta de Ementa}

\author{
Course description
}

\section{INTRODUÇÃO}

Parte-se da premissa de que há uma relação dialética entre as problemáticas relacionadas ao espaço urbano e rural, e estas com o meio ambiente. Os determinantes fundamentais para compreender essa relação situam-se na forma de organização da sociedade burguesa fundada na reprodução ampliada do capital que garante a acumulação e concentração da riqueza e da propriedade, e é a gênese da questão social entendida como a contradição entre a produção social e apropriação privada da riqueza. O constante aumento da produtividade do trabalho, condição para garantir a reprodução ampliada do capital, leva a um profundo processo de exploração e expropriação dos trabalhadores, aprofundando, ainda mais, a concentração da riqueza e exploração do trabalho.

O Estado, por sua vez, capturado pela burguesia, torna-se o agente regulador das relações socais e, principalmente, das tensões e dos conflitos entre as classes. As lutas sociais, expressões das contradições produzidas no processo de expropriação e exploração capitalista, se opõem à ordem capitalista e, em tempos de capital fetiche (IAMAMOTO, 2007), verifica-se o acirramento das contradições da ordem do capital.

As expressões desses processos no Brasil são mais intensas à medida que a formação do Capitalismo periférico subordinado aos 
interesses do Capitalismo central revela, em níveis mais aprofundados, a concentração da riqueza e da propriedade. Essa lógica se reproduz em todas as esferas da vida, na produção/reprodução, tanto no urbano quanto no agrário. A agricultura não foge a essa regra e se torna mais um setor subordinado à lógica da acumulação capitalista. A terra, um bem natural finito, se torna mercadoria e produz renda ao capitalista, cujo sistema tem, na "[...] terra e no trabalhador, as fontes originais de toda a riqueza" (MARX, 1971, p. 578-579). A organização dos movimentos sociais e a luta pela terra se contrapõem a esse processo e colocam a necessidade de democratização da propriedade no campo. A reforma agrária torna-se a bandeira de luta de uma diversidade de movimentos que se expressam nas mais variadas formas. Essas lutas sinalizam a urgência do enfrentamento de outras questões, tais como: a educação, saúde, habitação, políticas agrícolas, políticas para jovens, etc.

Em tempos de mundialização financeira, de políticas neoliberais e de crise do capital, a qual apresenta variadas dimensões - política, economia, ética, ambiental, financeira (CHESNAIS, 2005) - a reflexão e a pesquisa sobre a questão urbana ganha relevância devendo compreender, necessariamente, a análise crítica dos processos sociais, econômicos e políticos presentes no meio urbano, espaço privilegiado de localização dos grandes centros de comando, de decisão e de poder, de concentração de riqueza, mas, ao mesmo tempo, de mobilizações e de lutas sociais. As cidades se destacam como ponta de lança da ofensiva capitalista desde os primórdios da industrialização - notadamente com a concentração de força de trabalho, formada, na sua maioria, por camponeses que não tinham garantidas suas condições mínimas de sobrevivência no espaço agrário e ainda passaram por um processo de expropriação das suas terras pelo capital, sendo levados às cidades na busca da vida melhor prometida pelo capital no processo de industrialização. Ela se reconfigura, espacialmente, a cada mudança no padrão de urbanização, na forma de organização e de gestão do trabalho: a cidade da manufatura, a cidade da grande indústria, a cidade global, ou cidade da era da informatização e da informalização.

Todavia, traços comuns das contradições que marcam as formações sociais capitalistas são impressos nos espaços urbanos, sob a forma de segregação socioespacial, de concentração de terras, 
e de capitais e de acesso desigual aos bens e serviços presentes e disponíveis nestes espaços. Nas cidades dos países periféricos, a questão urbana assume contornos cruéis, justificando-se falar em barbárie urbana, dada a incidência, os índices e as formas de violência e de negação de direitos, além das precárias condições de moradia e de vida das camadas mais pobres (COUTINHO, 2004).

Nos anos mais recentes, o processo de modernização conservadora, que teve impacto tanto na cidade como no campo, manteve e aprofundou a concentração de terras e de riquezas, engendrando formas de especulação fundiária e imobiliária nas cidades, aprofundado as desigualdades entre as classes sociais, tanto no campo quanto nas cidades, e intensificou o uso predatório da natureza.

A problemática ambiental torna-se, então, uma das grandes questões do tempo presente, principalmente porque, nessa fase, o Capitalismo se sustenta na máxima exploração dos bens naturais (CHESNAIS; SERFATI, 2003), revelando uma contradição crescente entre as necessidades de expansão da produção e as condições do planeta para prover esse desenvolvimento, posto que os recursos ambientais do planeta estão cada vez mais comprometidos pelo uso predatório do espaço.

A dinâmica destrutiva do sistema se mantém e se aprofunda a despeito do avanço das discussões sobre a necessidade de preservação/conservação dos bens naturais e dos investimentos realizados neste campo, seja por meio da adoção de novas tecnologias, da intensificação dos processos de educação ambiental, ou mesmo da incorporação de indicadores socioambientais nas estratégias de negócio das empresas. O Capitalismo contemporâneo, marcado pela crise do capital, acentua esta tendência, interpelando os movimentos sociais, políticos, culturais e intelectuais e profissionais, exigindo-lhes avanços tanto no âmbito da interpretação destes fenômenos quanto no plano da ação cotidiana (SILVA, 2010).

Apreender a dinâmica atual da sociedade capitalista, que, historicamente, engendra o agravamento das desigualdades sociais geradoras de situações de pauperismo tanto no campo quanto na cidade e que promove o uso predatório dos recursos ambientais tem se relevado desafio incontornável para a área de serviço social, impondo-nos o exercício permanente da reflexão crítica contra as 
violações dos direitos, a mercantilização das cidades e da intensificação da desigualdade social por meio de uma estrutura fundiária que concentra terra, riqueza e renda.

Aprofundar a construção de fundamentos teórico-metodológicos, em uma perspectiva de totalidade, para embasar a análise crítica das expressões da questão social no âmbito da questão agrária, urbana e ambiental, em sua materialidade na realidade brasileira, bem como sobre as estratégias de intervenção profissional nestes campos, é a proposição deste Grupo de Trabalho.

Neste sentido, estamos propondo os seguintes eixos:

I - Determinações estruturais e históricas da questão urbana, agrária e ambiental no Brasil: a luta de classes como mediação.

1. Formas de apropriação, uso e ocupação do solo urbano e rural. Propriedade privada da terra, trabalho e formas de produção e reprodução capitalista. Apropriação privada dos recursos naturais; Impactos da reconfiguração das atividades econômicas no campo e na cidade sobre o mundo do trabalho;

2. Economia política do desenvolvimento. Modo de desenvolvimento capitalista, o papel do estado, e a particularidade brasileira e latino-americana: concentração fundiária, a constituição das classes sociais, o patrionalismo e o autoritarismo;

3. Mundialização do capital e manifestações contemporâneas da crise estrutural do capital na cidade e no campo, implicações no mundo do trabalho e na organização política dos trabalhadores: agronegócio, novas implantações industriais, monocultura, destrutividade ambiental; e processos de urbanização a partir de uma análise macro da estrutura societária;

4. Particularidades e desigualdades do desenvolvimento regional, a Amazônia e outras regiões do país, que sofrem um processo intensivo de expropriação pelo capital, e seu papel no desenvolvimento capitalista.

\section{II - O papel do Estado e as políticas públicas no campo e na cidade}

1. Políticas urbanas e o direito à cidade;

2. Dinâmicas socioeconômicas e formas de apropriação, planejamento, uso e gestão dos territórios;

3. Regulação Pública do meio ambiente e o discurso da sustentabilidade; 
4. Política agrária: trabalho, propriedade privada da terra, soberania alimentar, transgenia, agrotóxicos, mecanização intensiva e combate à fome.

III - Invisibilidade ou visibilidade negativa dos movimentos sociais de luta pela terra na cidade e no campo

1. Lutas sociais - especificidades dos movimentos sociais urbanos e rurais; processo de urbanização e a luta pela moradia;

2. Disputa por hegemonia e os distintos projetos de desenvolvimento agrário: assentados, camponeses e agronegócio etc.;

3. Processos migratórios e a função social da terra: a luta dos negros, indígenas e quilombolas pela terra no campo e na cidade;

4. Os movimentos sociais ambientalistas e as formas de regulação do Estado; a proteção ambiental em defesa da vida humana e dos recursos naturais;

5. Modos de vida e a crítica ao pensamento "Pós-moderno": o confronto ideológico na interpretação da vida cotidiana.

IV - A atuação do Serviço Social em face das refrações da questão agrária, urbana e ambiental: possibilidades e limites

1. Gestão ambiental pública e privada e o Serviço Social;

2. O Serviço Social e a educação ambiental crítica;

3. Formação profissional e questão urbana, agrária e ambiental;

4. Transformações estruturais no campo e na cidade, e seus rebatimentos no Serviço Social sob três dimensões: da formação, do trabalho e da organização política dos assistentes sociais.

\section{REFERÊNCIAS}

CHESNAIS, F. A finança mundializada. São Paulo, Boitempo, 2005. CHESNAIS, F.; SERFATI, C. "Ecologia" e condições físicas de reprodução social: alguns fios condutores marxistas. Revista Crítica Marxista, São Paulo, n. 16, mar. 2003.

COUTINHO, Ronaldo. Direito Ambiental das Cidades: questões teórico-metodológicas. In: COUTINHO, R.; ROCCO, R. (Org.). O Direito Ambiental das Cidades. Rio de Janeiro: DP\&A, 2004.

IAMAMOTO, M. V. Serviço Social em tempo de capital fetiche: capital financeiro, trabalho e questão social. São Paulo: Cortez, 2007. MARX, Karl. O Capital: (Crítica da economia política): livro 1, v.1: O 
processo de produção capitalista. 2. ed. Trad. Reginaldo Sant'Anna. Rio de Janeiro: Civilização Brasileira, 1971. p. 578-579.

SILVA, Maria das Graças e. Questão ambiental e desenvolvimento sustentável: um desafio ético-político ao Serviço Social. São Paulo: Cortez, 2010. 